\title{
Medical and morbidity surveillance findings among employees potentially exposed to TCDD
}

\author{
G G BOND,${ }^{1}$ M G OTT, ${ }^{1}$ F E BRENNER,${ }^{2}$ AND R R COOK ${ }^{1}$ \\ From US Area Medical' and Michigan Division Medical, ${ }^{2}$ Dow Chemical USA, Midland, Michigan 48640, \\ USA
}

\begin{abstract}
Available medical and morbidity surveillance findings from 1976 to 1978 for two employee cohorts potentially exposed to 2,3,7,8-tetrachlorodibenzo-p-dioxin (TCDD) were compared with those of matched unexposed employees. The medical surveillance findings were derived from a screening programme offered to all active employees and included an analysis of various medical history questions and blood chemistry results. Group medical insurance claims served as the source of morbidity surveillance data and the period prevalence of selected diseases was analysed. Few significant differences between the exposed and unexposed were detected. Among the cohort of employees potentially exposed during the manufacture of 2,4,5trichlorophenoxyacetic acid $(2,4,5,-\mathrm{T})$, a significantly greater frequency of $x$-ray proved ulcer was reported and significantly more members of this group had diseases of the digestive system diagnosed. Such findings were absent in the more highly TCDD-exposed cohort engaged in 2,4,5-trichlorophenol production, making it unlikely that dioxin was a cause.
\end{abstract}

The trace impurity 2,3,7,8-tetrachlorodibenzo-pdioxin (TCDD) is formed as a byproduct during the manufacture of 2,4,5-trichlorophenol (TCP) under alkaline conditions at raised temperatures and high pressures. Since TCP is a precursor for the production of the herbicide 2,4,5-trichlorophenoxy acetic acid $(2,4,5-\mathrm{T})$, low level contamination of the herbicide by TCDD is expected. Thus the potential for occupational exposure to TCDD may arise among employees making either TCP or 2,4,5-T.

Recent evidence suggests that TCDD may also be formed during the routine combustion of carbonaceous fuels. ${ }^{1}$ Chlorinated dioxins have been found in trace amounts in samples gathered from incinerator stacks as well as from chemical tar burners and a fossil fuelled power plant, vehicle silencers, fireplaces, chimneys, cigarette smoke, and portions of charcoal broiled steaks.

Mortality studies and case summaries of occupational cohorts presumably exposed to high levels of TCDD during the production of TCP, or exposed to lower levels during the synthesis of 2,4,5-T, have been published ${ }^{2-9}$ (J A Zack, unpublished observations). Reports have appeared of soft tissue sarcoma among employees with exposure severe enough to

Received 11 August 1982

Accepted 30 September 1982 cause chloracne ${ }^{5-7}$; however, no consistent unique mortality patterns have been noted among those with lower level exposure' (J A Zack). A survey of reproductive outcomes among wives of employees exposed to dioxins was also recently completed and indicated no biologically important associations. ${ }^{10}$ Available evidence suggests that occupational cohorts exposed to lower levels of TCDD in the manufacture of 2,4,5-T experience no important long term health risks.

Investigations, including the evaluation of health examination findings and morbidity data for TCDD-exposed individuals with long latency, have only recently been started. ${ }^{11}$ Clinical follow up 10 years later of 41 out of 79 individuals who developed chloracne in a 1968 TCP production accident, showed that other than minor persistent chloracne, there was no evidence of adverse health effects. ${ }^{12}$ While relatively little data are available from sound epidemiological follow up of other exposed cohorts, reported systemic health effects after exposure to large amounts of TCDD include impaired liver function, nephropathy, gastrointestinal irritation, myopathy, and neuropathy, including depression and irritation of the central nervous system. These symptoms have not been progressive and have been reported to disappear with time. Vietnam war veterans, presumably exposed to lower levels of 
TCDD and for shorter periods than industrial cohorts, have alleged a number of medical complaints-for instance, weight loss, liver damage, recurrent rashes, deformed offspring, stillbirths, cancer, sterility, personality changes, and "other" illnesses-which they attribute to their exposure to Agent Orange. ${ }^{11}$ To date, there have been no well controlled epidemiological studies to substantiate the allegations that these complaints are attributable to exposure to the trace amounts of TCDD in Agent Orange.

Medical follow up of inhabitants of Seveso exposed to TCDD as a result of an explosion of a trichlorophenol reactor has continued to document a lack of severe lasting health effects. While the findings are still regarded as preliminary, no organs or body functions, except the skin, have been found to be impaired; no excessive derangement of gestation, fetal lethality and loss, gross malformations, growth retardation at term or cytogenetic abnormalities have yet occurred. ${ }^{13}$

The present study reports the cross sectional medical and morbidity surveillance findings from 1976 to 1978 among employees at Dow Chemical, Michigan, who were considered potentially exposed to TCDD and for whom mortality surveys have been reported. ${ }^{29}$ The objective of the present investigation was to determine whether patterns of selected health examination findings from the routinely administered medical surveillance examination, and indices of morbidity as reflected in medical insurance claims for employees potentially exposed to TCDD, differed from those of employees not exposed.

\section{Methods and materials}

The study population was assembled from two previously identified cohorts: (1) a group of employees who had been engaged in the manufacture of 2,4,5-T for at least one month between 1950 and 1971 and (2) a cohort of employees involved in a 1964 chloracne incident in the area of TCP production.

The methods for the selection of these cohorts have been described previously. ${ }^{29}$ Briefly, the 204 white men comprising the 2,4,5-T cohort were identified from annual department census lists and work history records as having worked one month or longer between 1950 and 1971 on one of four job assignments (reactor operator, salt wheel operator, acid wheel operator, or dryer operator) in the $2,4,5$-T process. The TCP cohort of 61 white male employees was identified from monthly department census lists and lists of maintenance personnel who were known to have worked in the process area during a 1964 chloracne incident. The two cohorts have been considered separately in the analysis to allow for differences in their potential for TCDD exposure, and for differences in their exposures to other agents.

Data of interest were derived from two separate sources: health examination findings from the routinely administered medical surveillance programme and morbidity surveillance as reflected in diagnoses from external medical service providers reported for payment of fee to the group insurance department.

The medical surveillance examination has been offered to all employees since 1967. The time required for the programme to cycle through the entire manufacturing complex is about two years. Only cohort members who had participated in a medical surveillance examination between 1976 and 1978 were eligible for consideration for this portion of the study.

Controls for the medical surveillance analyses were selected from among other white men employed at this location who had also participated in such an examination between 1976 and 1978. Employees considered at high risk because of a history of a job assignment as a pipe coverer, in the production or packaging of arsenical pesticides, considered as potentially exposed to high levels of vinyl chloride, or potentially exposed to dioxins were excluded from consideration as potential controls. Four controls were then matched from those eligible to each exposed on year of birth \pm five years, whether hourly or salaried, smoking habit (never smoker, ex-smoker, current smoker) and, when possible, month and year of the most recent medical surveillance examination taken. When more than four controls were eligible for matching, the four with the date of hire nearest that of the exposed were selected.

Based on a review of relevant reports on animal and human exposure to TCDD, seiected medical history questions and blood chemistry results were considered for analyses. The matching was retained throughout. For the dichotomous questionnaire responses (yes or no), the analysis was that which has been proposed for a fixed $R: 1$ matching ratio with $\mathrm{R}=4 .^{14}$ Exact confidence limits were calculated with $\alpha=0.10$ using a packaged set of programmes for a programmable calculator. ${ }^{15}$ Blood chemistry values for each exposed subject were contrasted with the mean for the four matched controls, and a paired $t$-test was used to test the hypothesis that the mean difference between the exposed and matched controls was zero. Linear regression was done to test the correlation between $\log _{10}$ (days of employment in 2,4,5-T production) and the difference in blood chemistry values. 
Group medical insurance claims filed by employees for medical expenses incurred between 1 January 1976 and 31 December 1978 served as the source of morbidity data. Members of the original study cohorts who were eligible for benefits on 31 December 1978 from the Medical Care Programme administered by the group insurance department were included for study. This time restriction ensured that morbid events reported were independent of mortality as reported in earlier studies of these cohorts. ${ }^{29}$ Controls for morbidity comparisons were selected from among all white male employees eligible for Medical Care Programme benefits as of 31 December 1978. Employees with a history of certain job assignments were excluded from consideration as controls, as has been described above. From among the pool of eligible controls, four were matched to each exposed on the basis of year of birth \pm five years, and whether hourly or salaried. When more than four controls were eligible, the four with the date of hire nearest that of the exposed were selected.

Diagnoses and expense dates were abstracted from Medical Care Programme claims by a registered nurse, who was unaware of the exposure status of the subjects. Only diagnoses for claims for hospital inpatient care, hospital outpatient care, surgery, diagnostic expenses, or emergency first aid were considered. This excluded diagnoses from physician office visits, unless diagnostic expenses were incurred or surgery was done, and information from drug prescriptions. No validation of diagnoses with any external source was attempted.

Coding of diagnoses to the international classification of diseases-ninth revision-clinical modification (ICD-9-CM) was done by trained coders without knowledge of the exposure status of subjects. Diagnostic categories of interest were derived based on the relevant animal and human toxicology data.

An individual could contribute, at most, only one observation to each diagnostic category. Period prevalence of all cancer, various site specific malignancies, diseases of porphyrin metabolism, digestive system diseases, hepatic disorders, renal disorders, and diseases of skin and subcutaneous tissue was compared, using an analysis that maintained the matching. ${ }^{14}$

\section{Results}

\section{DEMOGRAPHIC CHARACTERISTICS}

Table 1 presents the vital and employment status distributions for the two cohorts, together with eligibility for the medical surveillance and morbidity surveillance portions of the study. Two years of
Table 1 Vital and employment status of exposed cohorts as of 31 December 1978. (Percentage of original cohorts in parentheses)

\begin{tabular}{llc}
\hline Status & TCP cohort & $2,4,5-T$ cohort \\
\hline Original & 61 & 204 \\
Employed & 40 & 116 \\
Retired & 11 & 21 \\
Deceased & 4 & 11 \\
$\begin{array}{l}\text { Left other than through retirement: } \\
\quad \text { Deceased }\end{array}$ & 0 & 56 \\
$\begin{array}{l}\text { Known alive } \\
\quad \text { Unknown }\end{array}$ & 6 & 2 \\
$\begin{array}{l}\text { Participated in medical surveillance } \\
\text { exam }\end{array}$ & 0 & 52 \\
$\begin{array}{l}\text { Eligible for medical care } \\
\text { programme and morbidity } \\
\text { surveillance }\end{array}$ & $27(44)$ & $87(43)$ \\
\hline
\end{tabular}

additional follow up with company records of the 2,4,5-T cohort identified two deaths not previously reported-one from cerebrovascular disease and the other from cardiovascular disease. Some $44 \%$ of the original 61 members of the TCP cohort and $43 \%$ of the 204 members of the 2,4,5-T cohort participated in medical surveillance examination between 1976 and 1978. Of those who were actively employed and thus eligible to participate, $68 \%$ of the TCP cohort and $72 \%$ of the $2,4,5-\mathrm{T}$ cohort did so. These participation rates are significantly lower than the participation rate of $80 \%$ among all other white men employed at this location $(p=0.04$ and $p=0.02$, respectively). Of the 49 individuals in the original TCP cohort who had evidence of acne like lesions in 1964, 22 participated in a medical surveillance examination. Nearly all members of both cohorts ( $94 \%$ of TCP and $97 \%$ of $2,4,5-T$ ), who were active or retired, were eligible for medical care programme benefits and thus could be surveyed for morbidity in this study.

Table 2 presents a comparison of demographic data for the subsets of each original cohort eligible for the medical surveillance examination and for morbidity surveillance and their matched controls. The exposed cohorts and their matched controls compared well with respect to all variables considered. In the analysis, potential confounding by cigarette smoking, age, year of hire, and socioeconomic status was controlled by matching and stratification on these variables or correlates.

\section{MEDICAL SURVEILLANCE FINDINGS}

Table 3 presents a comparison of the frequency of positive screens with selected questions from the medical surveillance examination for the two exposed cohorts and their matched controls. The frequency of positive screens was low for nearly all the questions, and the exposed and controls responded comparably. The only statistically 
Table 2 Comparison of exposed cohorts and their matched controls on selected demographic variables

\begin{tabular}{|c|c|c|c|c|}
\hline Demographic variable & TCP cohort & Controls & $2,4,5-T$ cohort & Controls \\
\hline $\begin{array}{l}\text { Medical surveillance: } \\
\text { No eligible for study } \\
\text { Mean age } \pm \text { SD } \\
\text { Year of hire } \\
\text { Salaried } \\
\text { Paid by the hour } \\
\text { Current smoker } \\
\text { Ex-smoker } \\
\text { Non-smoker }\end{array}$ & $\begin{array}{l}27 \\
45.4 \pm 7.6 \\
1953 \cdot 6 \pm 7.9 \\
5 \\
22 \\
6 \\
10 \\
11\end{array}$ & $\begin{array}{l}108 \\
45 \cdot 4 \pm 7 \cdot 8 \\
1953 \cdot 3 \pm 9 \cdot 2 \\
20 \\
88 \\
24 \\
40 \\
44\end{array}$ & $\begin{array}{l}87 \\
42 \cdot 8 \pm 8 \cdot 2 \\
1957 \cdot 1 \pm 8 \cdot 5 \\
14 \\
73 \\
25 \\
37 \\
25\end{array}$ & $\begin{array}{l}348 \\
42 \cdot 8 \pm 8 \cdot 3 \\
1956 \cdot 6 \pm 10 \cdot 0 \\
56 \\
292 \\
100 \\
148 \\
100\end{array}$ \\
\hline $\begin{array}{l}\text { Morbidity surveillance: } \\
\text { No eligible for study } \\
\text { Mean age } \pm \text { SD } \\
\text { Year of hire } \\
\text { Salaried } \\
\text { Paid by the hour }\end{array}$ & $\begin{array}{l}48 \\
49 \cdot 2 \pm 9 \cdot 5 \\
1951 \cdot 4 \pm 8 \cdot 0 \\
5 \\
43\end{array}$ & $\begin{array}{l}192 \\
49.2 \pm 9.6 \\
1951.7 \pm 10.5 \\
20 \\
172\end{array}$ & $\begin{array}{l}135 \\
45 \cdot 3 \pm 10 \cdot 2 \\
1956.7 \pm 7.9 \\
17 \\
118\end{array}$ & $\begin{array}{l}540 \\
45 \cdot 3 \pm 10 \cdot 2 \\
1955 \cdot 0 \pm 10 \cdot 6 \\
68 \\
472\end{array}$ \\
\hline
\end{tabular}

Table 3 Frequency of positive screens to selected medical surveillance examination questions among TCP and 2,4,5-T cohorts and matched controls, most recent exam 1976-8

\begin{tabular}{|c|c|c|c|c|}
\hline \multirow[t]{2}{*}{ Question } & \multicolumn{2}{|l|}{ TCP cohort } & \multicolumn{2}{|l|}{$2,4,5-T$ cohort } \\
\hline & $N_{E}(n=27)$ & $N_{C}(n=108)$ & $N_{E}(n=87)$ & $N_{C}(n=348)$ \\
\hline $\begin{array}{l}\text { Since your last Dow physical exam or health } \\
\text { inventory, have you had any of the following? } \\
\text { Skin trouble } \\
\text { Yellow jaundice } \\
\text { Problems with urination } \\
\text { Albumin or sugar in urine } \\
\text { Blood in urine } \\
\text { Frequent indigestion or heartburn } \\
\text { Intestinal trouble } \\
\text { Loss of weight } \\
\text { Coughing up of blood } \\
\text { Change in bowel habits } \\
\text { Blood in stools } \\
\text { Tarry stools }\end{array}$ & $\begin{array}{l}2 \\
0 \\
0 \\
0 \\
0 \\
0 \\
0 \\
0 \\
0 \\
0 \\
0 \\
0\end{array}$ & $\begin{array}{l}5 \\
0 \\
0 \\
0 \\
1 \\
5 \\
0 \\
4 \\
0 \\
0 \\
1 \\
1\end{array}$ & $\begin{array}{l}6 \\
0 \\
1 \\
0 \\
0 \\
4 \\
1 \\
3 \\
0 \\
0 \\
0 \\
0\end{array}$ & $\begin{array}{r}14 \\
0 \\
5 \\
3 \\
2 \\
19 \\
2 \\
6 \\
1 \\
0 \\
2 \\
1\end{array}$ \\
\hline $\begin{array}{l}\text { Do you have or have you had any of the following? } \\
\text { High blood pressure } \\
\text { Liver trouble (hepatitis) } \\
\text { Kidney or bladder trouble } \\
\text { Cancer or malignant growth } \\
x \text {-ray proved ulcer }\end{array}$ & $\begin{array}{l}1 \\
1 \\
2 \\
0 \\
2\end{array}$ & $\begin{array}{l}7 \\
4 \\
7 \\
0 \\
7\end{array}$ & $\begin{array}{l}6 \\
2 \\
5 \\
0 \\
9^{*}\end{array}$ & $\begin{array}{r}24 \\
12 \\
19 \\
3 \\
18\end{array}$ \\
\hline
\end{tabular}

${ }^{*} R_{M I}=2 \cdot 11 ; X_{M H}=1 \cdot 78,90 \% \mathrm{CI}=1.06-4 \cdot 20$.

$\mathrm{N}_{\mathrm{E}}=$ Number of exposed responding "Yes."

$\mathrm{N}_{\mathrm{C}}=$ Number of controls responding "Yes."

significant difference was the greater frequency of positive screens for $x$-ray proved ulcer among members of the $2,4,5-\mathrm{T}$ cohort $\left(\mathrm{R}_{\mathrm{ML}}=2 \cdot 11,90 \% \mathrm{CI}=\right.$ $1 \cdot 06-4 \cdot 20)$, based on nine of those exposed having reported such a history. As asked, the question of $x$-ray proved ulcer does not discriminate between incidence or prevalence, so the temporal relation between exposure and disease is not known.

Table 4 presents a comparison of results for nine selected blood chemistry tests performed as a part of the medical surveillance examination. Mean total bilirubin was slightly lower in both exposed cohorts and mean serum aspartate transaminase was lower in the 2,4,5-T cohort than in their respective controls; and while these differences were statistically significant at $\alpha=0 \cdot 10$, two tailed, they were not regarded as clinically significant. Given the number of comparisons done and the level of accepting a type 1 error, some statistically significant differences were to be expected.

When the mean difference between blood chemistry values for the exposed and their matched controls was regressed against $\log _{10}$ (days of employment in 2,4,5-T), there was a lack of significant association for all laboratory tests except for a significant positive slope for blood urea nitrogen (p 0.022); however, the independent variable explained only $6 \%$ of the variability in the dependent variable, suggesting that duration of employment in 2,4,5-T was not an important determinant.

Analyses of medical surveillance findings among only those members of the TCP cohort who had 
Table 4 Comparison of exposed cohorts with matched controls for nine selected laboratory tests, most recent medical surveillance examinations $1976-8$

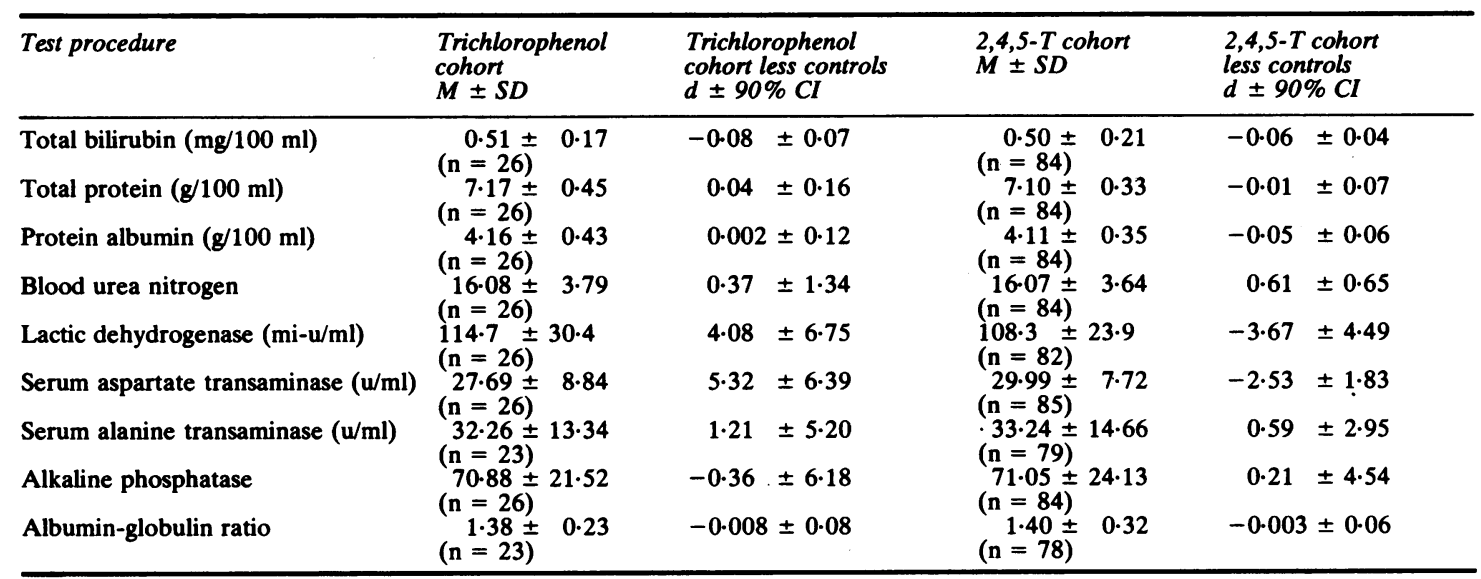

( $\mathrm{n}=$ Number of matched quintuplets)

Table 5 Comparison of number of prevalent cases of selected disease conditions by exposure group: diagnoses from Medical Care Programme, 1976-8

\begin{tabular}{|c|c|c|c|c|}
\hline \multirow[t]{3}{*}{ Disease category } & \multicolumn{4}{|c|}{ No of prevalent cases } \\
\hline & \multicolumn{2}{|l|}{ TCP cohort } & \multicolumn{2}{|l|}{ 2,4,5-T cohort } \\
\hline & $N_{E}(n=48)$ & $N_{C}(n=192)$ & $N_{E}(n=135)$ & $N_{C}(n=540)$ \\
\hline \multirow{3}{*}{$\begin{array}{l}\text { Malignant neoplasms (140-209) } \\
\text { Mn of liver (155) } \\
\text { Mn of trachea, bronchus, and lung (162) } \\
\text { Mn of connective and other soft tissue (171) } \\
\text { Mn of skin (172-173) } \\
\text { Malignant lymphoma (200-202) } \\
\text { Diseases of porphyrin metabolism (277.1) } \\
\text { Diseases of the digestive system excluding liver } \\
\text { disease }(530-535,555558,564 \cdot 1) \\
\text { Disorders of the liver }(570-573) \\
\text { Glomerulonephritis }(580-583) \\
\text { Renal failure }(584-586) \\
\text { Infections of kidney (590) } \\
\text { Diseases of skin and subcutaneous tissues } \\
\text { (680-686, 692, 695) }\end{array}$} & $\begin{array}{l}1 \\
0 \\
1^{*} \\
0 \\
0 \\
1^{*} \\
0\end{array}$ & $\begin{array}{l}4 \\
0 \\
0 \\
1 \\
1 \\
0 \\
0\end{array}$ & $\begin{array}{l}4 \\
0 \\
1 \\
0 \\
0 \\
0 \\
0\end{array}$ & $\begin{array}{l}9 \\
1 \\
1 \\
0 \\
2 \\
0 \\
0\end{array}$ \\
\hline & $\begin{array}{l}3 \\
0 \\
0 \\
0 \\
0\end{array}$ & $\begin{array}{r}10 \\
5 \\
0 \\
0 \\
0\end{array}$ & $\begin{array}{c}17 \dagger \\
2 \\
0 \\
0 \\
0\end{array}$ & $\begin{array}{r}27 \\
5 \\
0 \\
1 \\
0\end{array}$ \\
\hline & $\mathbf{0}$ & 2 & 2 & 11 \\
\hline
\end{tabular}

Refers to a single individual.

$\dagger R_{M L}=2.51 X_{M H}=2.957,90 \% C I=1.50-4.18$.

$\mathrm{N}_{\mathrm{E}}=$ Number of prevalent cases among exposed cohort.

$\mathbf{N}_{\mathbf{C}}=$ Number of prevalent cases among controls.

exhibited acne like lesions in 1964 produced similar results to the analysis of the total eligible cohort.

\section{MORBIDITY SURVEILLANCE FINDINGS}

Of the 915 members of the exposed cohorts and the matched control groups eligible for Medical Care Programme benefits, $656(71.7 \%)$ filed at least one claim for medical services during the study period 1976-8. A total of 6539 separate diagnostic entries were abstracted and coded and constituted the total morbidity data base from which the analyses of conditions of interest were carried out. The diagnostic entries were distributed fairly evenly across the study years with 2126 entries in 1976, 2245 in 1977 , and 2168 in 1978. Most of the diagnoses were on claims for physician's services $(58.4 \%)$ and claims for hospital services $(35.3 \%)$, with few diagnoses provided solely from laboratories $(4.7 \%)$ or other sources $(1.5 \%)$. About one quarter of all diagnoses provided were precoded to some disease categorisation scheme by the service provider.

Table 5 presents a comparison of the number of prevalent cases of disease conditions of interest for each of the exposed cohorts and their matched con- 
Table 6 Detailed breakdown of diseases of digestive system among 2,4,5-T cohort and matched controls. Diagnoses from Medical Care Programme, 1976-8

\begin{tabular}{llc}
\hline Disease category & \multicolumn{2}{l}{ No of prevalent cases } \\
\cline { 2 - 3 } & $N_{E}$ & $N_{C}$ \\
\hline Diseases of oesophagus (530) & 2 & 1 \\
Gastric ulcer (531) & 2 & 3 \\
Duodenal ulcer (532) & 3 & 3 \\
Peptic ulcer, site unspecified (533) & 2 & 7 \\
Gastrojejunal ulcer (534) & 0 & 0 \\
Gastritis and duodenitis (535) & 3 & 4 \\
Regional enteritis (555) & 0 & 1 \\
Other non-infectious gastroenteritis & & \\
$\quad$ and colitis (558) & 6 & 10 \\
Irritable colon (564-1) & 4 & 5 \\
\hline
\end{tabular}

Note: An individual may have more than one condition. $\mathrm{N}_{\mathrm{E}}=$ Number of prevalent cases among 2,4,5-T cohort. $\mathrm{N}_{\mathrm{C}}=$ Number of prevalent cases among matched controls.

trol groups. The period prevalence of most conditions was low and was comparable between the exposed and their controls. An exception was the significantly greater prevalence of diseases of the digestive system excluding liver disease among the $2,4,5-\mathrm{T}$ cohort $\left(\mathrm{R}_{\mathrm{ML}}=2 \cdot 51,90 \% \mathrm{CI}=1 \cdot 50-4 \cdot 18\right)$ based on 17 prevalent cases among the exposed. Table 6 gives a detailed breakdown of the distribution of prevalent cases among the 2,4,5-T cohort and their controls by disease within this category. The difference in prevalence cannot be explained on the basis of a preponderance of any one specific disease entity; instead, the 2,4,5-T cohort had relatively more cases of each condition.

\section{Discussion}

Results from this cross sectional examination of medical and morbidity surveillance findings among two cohorts who were potentially exposed to TCDD at some point in the past and their matched unexposed controls showed few differences. Those employees who were engaged in 2,4,5-T production at some point, between 1950 and 1971 , reported the prevalence of $x$-ray proved ulcer significantly more often than their matched controls, and recorded significantly more diagnoses of diseases of the digestive system. The lack of a similar finding among the more highly TCDD-exposed in the TCP cohort makes it unlikely that the dioxin is associated with this finding. The departmental unit under which the $2,4,5$ - $T$ process was first organised was also responsible for manufacturing various other products. Thus many of the individuals in the 2,4,5-T cohort were potentially exposed to numerous other substances during their employment with this unit.

The 2,4,5-T dust concentrations found in the plant were often high enough to be noticeably irritating, and were believed to have resulted primarily from finishing operations where the end product was dried and fed through a hammer mill. One could postulate that ingested dust could lead to a greater frequency of diseases of the digestive system. The 2,4,5-T exposures, however, were incurred by subjects in this study a minimum of five years before the indication of disease prevalence, thus making latency an important issue.

A limitation of cross sectional studies is the uncertainty surrounding the temporal sequence in the exposure disease relationship. As was the case in this study, it is usually not possible to discriminate between disease incidence and prevalence, so that one is uncertain whether or not the exposure preceded the disease and could possibly be a cause.

Data on health outcome from medical and morbidity surveillance of the two cohorts in the present study were limited to the active or recently retired workforce. Members of the two cohorts who left the company for reasons other than retirement could not be studied. Inferences from the present study concerning the health status of former employees must be drawn carefully owing to possible retirement of former employees on the basis of health.

The study was further limited to medical and morbidity surveillance for a three year period (1976-8). Owing to the large amount of time required to locate and code archived medical claims, a larger sample was deemed unfeasible.

With the completion of this study, these employees have now been surveyed for morbidity, mortality, and reproductive outcomes. To date, the available data do not indicate serious long term health risks associated with exposures to TCDD at the levels encountered by these two industrial cohorts. Consideration is being given to continued medical and morbidity surveillance of these cohorts, and we recommend that other cohorts with similar exposures also be surveyed.

We gratefully acknowledge the contributions of $\mathrm{Mr}$ Bernard Lasich, Mr Stewart Gudmundsen, Mrs Janice Cartmill, Mrs Jean Townsend, Mrs Elsie McLaren, Dr Robert Kolesar, and Mrs Angie Grzegorczyk of Dow Chemical, USA, and of Mr Larry Silverstein, formerly of Dow Chemical, USA, and now with the Dow Corning Corporation.

\section{References}

${ }^{1}$ Bumb RR, Crummett WB, Cuties SS, et al. Trace chemistries of fire: a source of chlorinated dioxins. Science 1980;210:385-9.

${ }^{2}$ Cook RR, Townsend JC, Ott MG, Silverstein LG. Mortality experience of employees exposed to 2,3,7,8-tetrachloro- 
dibenzo-p-dioxin (TCDD). JOM 1980;22:530-2.

${ }^{3}$ Zack JA, Suskind RR. The mortality experience of workers exposed to tetrachlorodibenzodioxins in a trichlorophenol process accident. JOM 1980;22:11-4.

4 Theiss AM, Frentzel-Beyme R. Mortality study of persons exposed to dioxin in a trichlorophenol-process accident that occurred in the BASF AG on November 17, 1953. American Journal of Industrial Medicine 1982;3:179-89.

'Honchar PA, Halperin WE. 2,4,5-T, Trichlorophenol and soft-tissue sarcomas. Lancet $1981 ; \mathrm{i}: 268-9$.

- Cook RR. Dioxin, chloracne, and soft-tissue sarcoma. Lancet 1981;i:618-9.

' Cook RR. Soft-tissue sarcomas: clues and caution. In: Tucker $\mathbf{R}$ Young AL, Gray AP, eds. Environmental science research and theory. Vol 26. Human and environmental risks of chlorinated dioxins and related compounds. New York: Plenum Publishing Corporation, 1983.

- International Agency for Research on Cancer. Evaluation of the carcinogenic risk of chemicals to humans. Some fumigants, the herbicides 2,4-D and 2,4,5-T, chlorinated dibenzodioxins and miscellaneous industrial chemicals. Lyon: IARC, 1977. (Monograph 15.)
- Ott MG, Holder BB, Olson RD. A mortality analysis of employees engaged in the manufacture of 2,4,5-trichlorophenoxyacetic acid. JOM 1980;22:47-50.

10 Townsend JC, Bodner KM, Van Peenen PFD, Olson RD, Cook RR. Survey of reproductive events of wives of employees exposed to chlorinated dioxins. Am J Epidemiol 1982;115:695-713.

"Council on Scientific Affairs Advisory Panel on Toxic Substances. The health effects of "Agent Orange" and polychlorinated dioxin contaminants. Chicago: American Medical Association, 1981.

12 May G. Tetrachlorodibenzodioxin: a survey of subjects ten years after exposure. $\mathrm{Br} J$ Ind Med 1982;39:128-35.

${ }^{13}$ Huff JE, Moore JA, Saracci R, Tomatis L. Long-term hazards of polychlorinated dibenzodioxins and polychlorinated dibenzofurans. Environ Health Perspect 1980;36:221-40.

${ }^{14}$ Miettinen OS. Estimation of relative risk from individually matched series. Biometrics 1970;26:75-86.

${ }^{15}$ Rothman K, Boice J. Epidemiologic analysis with a programmable calculator. Washington: US Government Printing Office, 1979:19-24. (NIH Publication No 79-1649.) 